\title{
SÕNADE TIIDE, TIIDAKIL JA TORU PÄRITOLUST
}

\author{
IRIS METSMÄGI
}

\begin{abstract}
Annotatsioon. Murdesõna tiide 'viltu, põiki' (tiideviltu, tiidevinti) on tõenäoliselt kujunenud laensõnast piidevint $(i)$ selle hälikulise varieerumise, rahvaetümoloogilise ümbermõtestamise ja lühenemise teel. Sõna tiidakil 'viltu vajunud; viltu' võib olla muu päritoluga, kuid tiide on mõjutanud selle kirjakeelset tähendust. Sõna toru võib olla vähemalt osaliselt läänemeresoome tüve *torvi 'sarv' deminutiivtuletis *torvo $(i)$, milles $v$ on labiaalvokaali ees kadunud.
\end{abstract}

Võtmesõnad: leksikoloogia, etümoloogia, eesti murded, eesti keel

\section{tiide ja tiidakil}

Eesti keele sõnaraamatud tunnevad murdelist adverbi tiide 'viltu, põiki', mis esineb ka samatähenduslikus liitsõnas tiideviltu. Nende kõrval esinevad kirjakeeles samatüvelistena näivad adverbid tiidakil 'viltu vajunud, ümber kukkumas; vildakil, viltu' ja tiidakile 'viltusesse asendisse, vildakile, viltu'. (EKSS 5: 771-772; ÕS 2018: 960; EKS)

Eesti 17.-18. sajandi sõnaraamatutes kõnealuseid sõnu tänapäevasele hääldusele vastaval kujul registreeritud ei ole, kuid August Wilhelm Hupeli sõnaraamatust leiame esimeses silbis $\ddot{u}$-häälikuga tüde wilto 'in die Quere' ['põiki'] (Hupel 1780: 289; 1818: 254). Esimene leksikograafiline allikas, kus sõnakuju tiide esineb, on minu andmetel Ferdinand Johann Wiedemanni sõnaraamatu esimene trükk: tīde 'schräg, nach der Diagonale, nicht senkrecht oder rechtwinkelig' ['viltu, diagonaalis, mitte püstloodis või täisnurga all']. Samuti on selles ära toodud liitsõna tīde-wiltu 'in der Quere' ['põiki'] ning sõnaühendid tīdel wiltu id. ja tīde winkel 'stumpfer Winkel' ['nürinurk']. Levikupiirkonna kohta ei ole andmeid esitatud. Ilmselt samatüveline on Hiiumaa sõna tīder : tīdre, mille tähendus on identne sõnaga tīde. (Wiedemann 1869: 1285) Ka sõna tīde oletatav 
foneetiline variant $t \overline{\ddot{u}} d e$ on registreeritud (1371): sõnaraamatu teises trükis ongi see paigutatud artiklisse tìde (Wiedemann 1973 [1893]: 1163). Sõnad tīdakil ja tīdakile lisanduvad sõnaraamatu teises trükis, kuid nende tähendus 'dreieckig zusammen gelegt' ['kolmnurkselt kokku murtud'] erineb mõnevõrra tänapäevasest; levikupiirkonnaks on märgitud LõunaViljandimaa (ibid.).

Andrus Saareste „Eesti keele mõistelisest sõnaraamatust“ leiame samuti tiide (koos Wiedemanni sõnaraamatust pärineva variandiga tüüde) 'viltu, diagonaalselt, mitte loodis, mitte rõhtsalt, mitte sirgnurga all' (levikupiirkond Hiiu- ja Saaremaa, Muhu, Kihnu, Läänemaa edelaosa, Tõstamaa, Audru, Häädemeeste lõunaosa, Rapla ja Keila lääneosa) ja tiideviltu, lisaks veel tiidemisi (Jämaja) ehk tiitamisi (Tarvastu) 'tiide, viltu' ning tiidaku 'tiidakil' (Risti) (EKMS IV: 552). Registreeritud on ka adjektiiv tiider (koos Wiedemanni sõnaraamatust pärinevaks märgitud variandiga tüüder, Hiiumaa) 'tiide olev, viltune, diagonaalne' (EKMS IV: 559) ja adverb tiidakil '(nelinurkne paber, rätik vm) kolmnurgaks kokku pandult' (Mulgimaa) (EKMS II: 57), 'pisut tiide' (EKMS IV: 552).

„Väikese murdesõnastiku“ ja Eesti murrete ja soome-ugri keelte arhiivi (EMSUKA) levikuandmed adverbide tiide ja tiideviltu (ka tiidevilta) kohta ühtivad laias laastus Saareste esitatud andmetega: sõnad on valdavalt levinud saarte murdes ja läänemurde Läänemaa osas, vähem on andmeid läänemurde Pärnumaa osast ning keskmurdest (peamiselt Harju- ja Järvamaalt). Sõna tiideviltu on registreeritud ka Mulgi murde alalt Karksist. Osis tiide-, mis näib identne eespool nimetatud sõnades leiduvaga, esineb ka üksikutes murrakutes kirja pandud liitsõnas tiidevinti 'poolviltu (tuul)'. Teated sõnade tiidakil ja tiidakile kohta on napid: vaid Kuusalust on registreeritud tiidagilla 'tiidakil, poolviltu', Risti kihelkonnast samatähenduslik tiidaku. Tarvastust on kirja pandud tiitämisi 'poolviltu'. (EMSUKA; VMS II: 505, 507; vt kaart 1) Vanemates allikates esineva, esimeses silbis vokaali $\ddot{u}$ sisaldava variandi tüüde kohta andmed puuduvad. Ei ole teada, kas Wiedemannil oli selle kohta muid andmeid peale Hupeli sõnaraamatu. Kuna $\ddot{u} \ddot{u} \sim i i$ vaheldust on eesti keele pinnalt raske seletada, ei saa välistada ümberkirjutusviga Hupeli sõnaraamatus vms. 


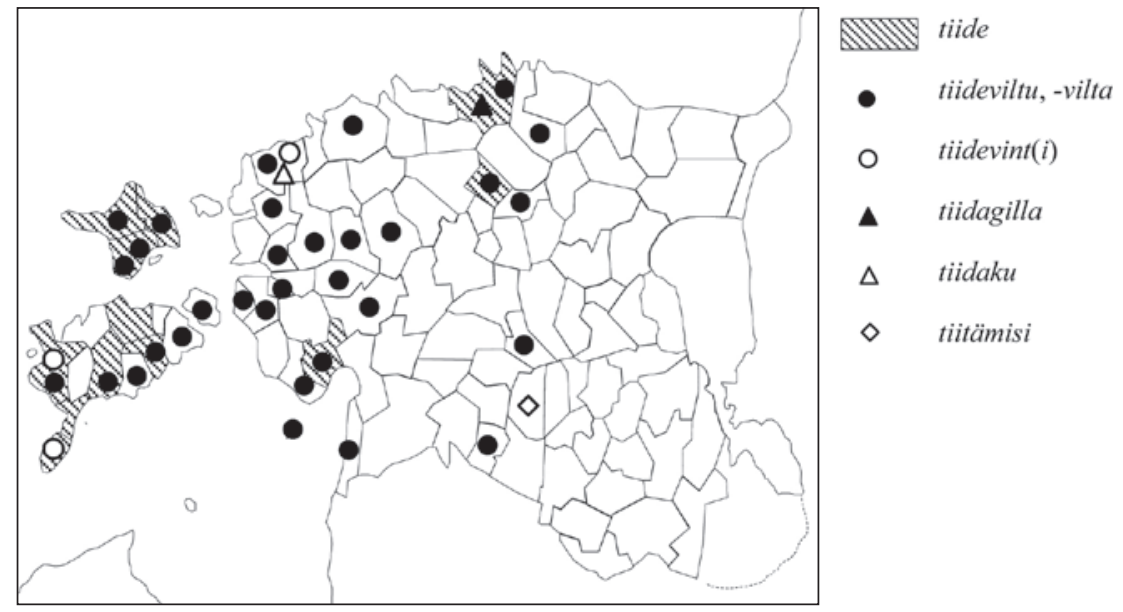

Kaart 1. tiide, tiideviltu, tiidevint(i), tiidagilla, tiidaku, tiitämisi eesti murretes

Johannes Aaviku „Uute sõnade sõnastikus“ on sõnad tiidakil ja tiideviltu esitatud sünonüümsena, tähendusega 'viltu, diagonaalis (mitte õiges vinklis või ristloodis)' (Aavik 1919: 45). tiide lisandub sõnastiku teises väljaandes, sõnakolmiku tähendus on 'viltu, diagonaalses, kergesti kukkuvas asendis'. Lisatud on märgend $m$, mis tähistab kirjakeeles seni vähe kasutatud murdesõnu, mida soovitatakse kasutusele võtta. (Aavik 1921: 116) Õigekeelsussõnaraamatutes esinevad tiidakil, tiidakile, tiide ja tiideviltu esimesest väljaandest alates (ÕS 1918: 121).

Etümoloogid ei ole sõnadele tiide ja tiidakil tähelepanu pööranud. Alo Raun märgib oma „Eesti keele etümoloogilises teatmikus“ sõna tiidakil päritolu ebaselgeks (Raun 1982: 175). Mulle teadaolevalt ainsa seletuskatse on teinud Julius Mägiste oma eesti etümoloogiasõnaraamatus, kus ta pakub välja, et tiidakil (millega etümoloogiliselt seotuks peab ta ka sõna tiide) võiks olla deskriptiivne ,deformatsioon“ sõnaga tiib seostuvast sõnast tiibakil ${ }^{1}$ (EEW: 3153). Kahjuks jääb EEWs täpsustamata, kuidas mainitud tiibakil võiks häälikuliselt ja morfoloogiliselt kujunenud olla ning kust selline sõna üldse pärineb. Vahest lähtub see Wiedemanni sõnaraamatus esinevast Lõuna-Viljandimaa sõnast tībak: tībaku'winkeliges Landstück' ['kõver, sopiline maatükk'] (Wiedemann 1973 [1893]: 1163;

${ }^{1}$ Originaalis trükiveaga tiibakib. tiibakil on seega minu tõlgendus. 
vt ka EKMS II: 780), mis on EEWs paigutatud sõna tiib tuletiste hulka (EEW: 3152) ja mida tõenäoliselt esindab ka hiljem Tarvastu murrakus kirja pandud tiibäk: tiibäku 'kolmenurkne', tiibäk tükk (EMSUKA; VMS II: 505). Võrreldagu ka „Väikeses murdesõnastikus“ adverbi tiivakile (V1l, JMd 'külili') foneetilise variandina esitatud, samuti Tarvastu murrakus registreeritud sõna tiibäkile 'viltu' (EMSUKA; VMS II: 507). Kuna Wiedemanni sõnaraamatus esinev tiidakil pärineb samast piirkonnast ehk Lõuna-Viljandimaalt ning ka (tänapäeva kirjakeelsest erinev!) tähendus 'kolmnurkselt kokku murtud' (vrd ka EKMS II: 57) peaaegu ühtib Tarvastu sõna tiibäk tähendusega 'kolmenurkne', siis võib Mägiste seletus kuigivõrd arvesse tulla. Variandi teket võib aga seletada pigem assimilatsiooniga, st sõnaalguline klusiil on mõjutanud sõnasisese klusiili kvaliteeti, või lihtsalt sporaadilise häälikuvaheldusega (sellest rohkem järgnevas). Siiski võib kahelda, kas sõnast tiidakil, mis on juhusliku varieerumise teel kujunenud suhteliselt kitsas piirkonnas levinud sõnast tiibak $\sim$ tiibäk, oleks saadud sekundaarne, abstraheeritud tüve esindav tiide, mis levis murretes juba märksa laiemale alale. Ka hilisemal ajal hoopis teises piirkonnas kirja pandud Kuusalu tiidagilla ja Risti tiidaku ei pruugi Wiedemanni sõnaga tiidakil otseselt seotud olla.

Järgnevalt esitan sõnale tiide omapoolse etümologiseerimiskatse. Nagu juba eespool mainitud, esineb osis tiide ka liitsõnades tiideviltu ja tiidevinti. Viimati nimetatu on ilmselgelt foneetiline variant sõnast piidevint $(i)$ (ka pidivinti), mis on kirja pandud peamiselt saarte ja kirderannikumurretes ligikaudse tähendusega 'vastutuult' (EMSUKA; VMS II: 200; vt kaart 2), ning on kasutusel ka kirjakeeles merendusterminina ${ }^{2}$ piidevint 'tihttuul, poolpõiki vastu puhuv tuul' (ÕS 2018: 687; EKS), nt Purjekas sõidab piidevinti 'vastutuult' (EKSS 4: 222). Etümoloogilist kokkukuuluvust kinnitavad EMSUKAs registreeritud näited ja selgitused: tiidevinti söitama 'purjepaadiga 3/4 vastutuult sõitma', tuul oo tiidevinti 'poolviltu tagant, vastu' (Kihelkonna), tiidevinti: knapist vastu tuult, nii knapist kui aga purjud võtvad (Risti).

Sõna piidevint $(i)$ on noorem laen, mis on selles mõttes erandlik, et laenualuseks ei ole mitte üksiksõna, vaid prepositsioonist, määravast artiklist ja nimisõnast koosnev fraas alamsaksa bi de wind resp. hollandi bij de(n) wind 'tihttuult', sõna-sõnalt 'tuule juures'. Hollandi või alamsaksa

\footnotetext{
2 2006. a ilmunud EKSS märgib sõna piidevint veel kõnekeelsena (EKSS 4: 222).
} 


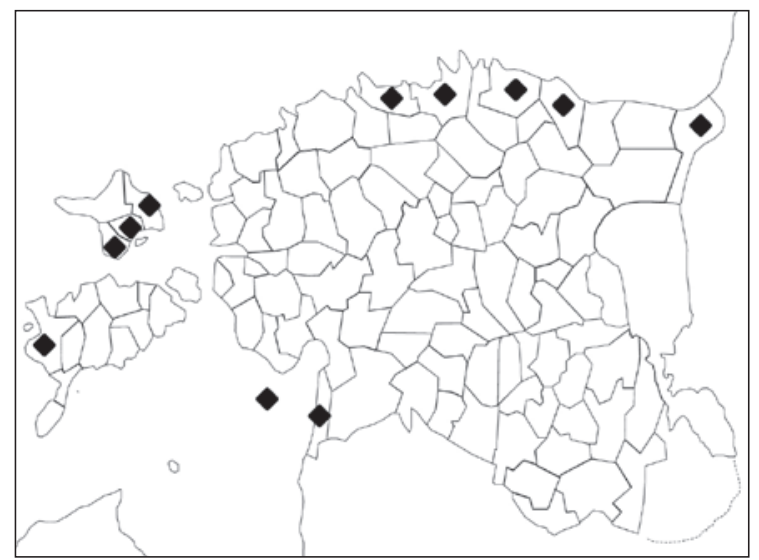

Kaart 2. piidevint(i), pidivinti eesti murretes

keelest on laen, nagu paljud teisedki merendussõnad, levinud kas otse või vahenduskeelte kaudu mitmesse Läänemere-äärsesse keelde, vrd nt rts bidevind ja sellest omakorda laenatud sm mrd pitivinni, pi(i)livinni (SKES: 580; SSA 2: 353). Eesti piidevint $(i)$ on laenatud arvatavasti rootsi keele vahendusel (EEW: 2021), laenuallikaks on peetud ka alamsaksa keelt (Ojansuu 1916: 173). ${ }^{3}$ Wiedemanni sõnaraamatus esineb see laen kahel kujul, nii lähtekeeltele omase sõnaalgulise klusiiliga ja eristatud fraasi komponentidega kui ka täiesti muganenult, vrd bì-de-wint' gegen den Wind (lavirend)' ['vastutuult (laveerides)'] (Wiedemann 1973 [1893]: 79) ja pídiwint puŕjutama 'bei dem, gegen den Wind segeln, pressen' ['piidevinti, vastutuult purjetama, suruma'] (Wiedemann 1869: 916; 1973 [1893]: 830).

Variandi tiidevint $(i)$ teket võiks seletada assimilatsiooniga, st sõnasisene klusiil on mõjutanud sõnaalgulise klusiili kvaliteeti. Laiemas mõttes näib sõnapaar piidevint $(i)$ - tiidevint( $(i)$ esindavat eesti murretele iseloomulikke sporaadilisi klusiilivaheldusi (vt nt Kobolt 1931: 153, allmärkus 4). Sagedastele klusiilivaheldustele sõna alguses $i$ ees on mu tähelepanu suuliselt juhtinud kolleeg Udo Uibo. Osaliselt võib selliseid vaheldusi seletada assimilatsiooni või dissimilatsiooniga, võrreldagu nt selliste nooremate laensõnade variante nagu tikerber - kikerber (ulatuslik murdelevik) (Wiedemann 1973 [1893]: 280; VMS I: 221-222; EMS III:

${ }_{3}$ Olen selles lõigus kasutanud Eesti Keele Instituudis pooleli oleva akadeemilise eesti etümoloogiasõnaraamatu käsikirja artiklit piidevint (koostanud Meeli Sedrik). 
111), piipkann - Trv Hel tiipkann (EMSUKA), piparmünt-Krk tippermünt (EMSUKA). Osaliselt aga ei ole põhjus selge, pandagu tähele nt selliseid paare nagu till (maitsetaim) - piĺlirohi (Wiedemann 1973 [1893]: 968), kihu 'midagi pisipeent; ivake, natuke' - pihu 'põrm, kübemeke', piiluma kiiluma tähenduses 'piiluma, pilke heitma, kiikama' (VMS I: 218; EMS III: 85-86), pill 'kalapõis' (VMS II: 208) - till id. (VMS II: 510). Arvatavasti moodustavad sporaadilised klusiilivaheldused ühe osa eesti murretele, aga ka teistele läänemeresoome keeltele iseloomulikest mitmesugustest sporaadilistest resp. fakultatiivsetest häälikuvaheldustest, mida on kirjeldanud nt J. Väinaste (1925), Osmo Nikkilä (1999), Lembit Vaba (2016: 253-256).

Sõna tiideviltu omakorda näib olevat piidevinti variandi tiidevinti rahvaetümoloogiline edasiarendus. Murdelevik sellisele kujunemiskäigule vastu ei räägi. Kõnelejad on keelendit tiidevinti ilmselt tõlgendanud liitsõnana ning asendanud semantiliselt ähmase osise vinti sisuliselt mõistetavama, häälikuliselt lähedase sõnaga viltu. Väärib märkimist, et Wiedemanni sõnaraamatus on registreeritud veel üks tõenäoliselt sõna piidevinti sõnaalgulisel sporaadilisel klusiilivaheldusel ja järelosise rahvaetümoloogilisel asendusel põhinev variant, kīde wiltu 'schief' ['viltu'] (Wiedemann 1869: 336; 1973 [1893]: 303). Järgmise sammuna on liitsõna tiideviltu järelosis ära jäetud ning selle tähendus on kandunud esiosisele tiide. Kaudselt toetab sellise lühenemise oletust asjaolu, et murretes on pikem tiideviltu kirja pandud hoopis sagedamini kui lühem tiide. Nõnda ongi tekkinud uus tüvisõna, esialgu instruktiivivormilisi adverbe meenutav tiide. Võimalik, et Põhja-Eesti üksikutes murrakutes registreeritud tiidagilla, tiidaku 'tiidakil, poolviltu' on moodustatud sellest tüvest, sõltumata Wiedemanni sõnaraamatus Lõuna-Viljandimaalt kirja pandud sõnast tiidakil 'kolmnurkselt kokku murtud'. Kirjakeele kohta näib aga usutavam, et tiide 'viltu, diagonaalis' on mõjutanud Wiedemanni sõnaraamatust pärineva, alguses ehk erineva päritoluga sõna tiidakil tähendust.

\section{$\operatorname{toru}^{4}$}

Sõnal toru 'pikk silindriline õõneskeha', kasutatav ka telefoni käes hoitava osa, korstna, püksisäärte, tulirelva või selle raua ja puhkpilli kohta (EKSS 5: 857-858; EKS), on läänemeresoome keeltes suhteliselt vähe

4 See artikli osa põhineb etümoloogilise võrgusõnaraamatu avaseminaril Helsingis 18.08.2018 peetud ettekandel „Eesti toru, soome toro päritolust“. 
vasteid. Etümoloogiasõnaraamatute andmeil kuuluvad nende hulka soome toro 'veski kolu; renn, toru; kannu tila', tori id.; 'korsten' ja eesti keelest laenatud liivi torī, to 'r 'toru, kannu tila', tor $\bar{u}$ 'tanu tipp' (SKES: 1351; SSA 3: 312; EES: 542). Ilmne vaste on ka (Tsvetkovi materjalides registreeritud) vadja toro 'toru' (VKS: 1301), mis on arvatavasti samuti eesti keelest laenatud.

Sõnaraamatutes esineb eesti toru esimest korda 17. sajandil Heinrich Gösekenil (1660), kuid mitte tänapäevases põhitähenduses, vaid ainult seoses puhkpillidega: Torro on sõnade Kram horn/ (Schalmey) lituus ['sarv, signaalpasun'] vaste ning esineb ka liitsõnas torro-Sarw, mis on antud saksa sõna Deuthorn ['karjasarv'] vastena (Kingisepp jt 2010: 667). Tänapäevane tähendus tuleb esile alates 18. sajandist. Nii on Anton Thor Helle sõnaraamatus torro 'die dicke Röhre im Dudelsack' ['torupilli jäme toru'] (Helle 1732: 190) ja August Wilhelm Hupeli sõnaraamatus 'kleine Seitenröhre an Pumpen und an Gießgefäßen; dicke Röhre am Dudelsacke' ['pumpade ja kastmisnõude väike külgtoru; torupilli jäme toru'] (Hupel 1818: 251) ${ }^{5}$. Wiedemanni sõnaraamatus on toru : toru (toro) põhitähenduse 'Röhre' kõrval esitatud nüansid 'Tülle, Bock- oder Basspfeife am Dudelsack, Heber, Mühlentrichter, Cylinder' ['(kannu)tila, torupilli bassivile, sifoon, veskikolu, torukübar'] (Wiedemann 1973 [1893]: 1175). Eraldi märksõnana on ära toodud variant tori : tori 1 ) 'Röhre, Rinne, Dachrinne, Ausgussröhre' ['toru, renn, katuserenn, tila']; 2) (piltl) 'Strom, Menge' ['vool, suur hulk'] (ibid.: 1173). Eesti murretes on toru $\sim$ toro põhitähendusega 'pikk silindriline õõneskeha' seostuvate esemete või nende osade, ka kehaosade nimetusena üldlevinud, variant tori esineb saarte murdes ja paaris Läänemaa murrakus (EMSUKA; VMS II: 528, 530; vt kaart 3).

Eesti toru, soome toro päritolu kohta on etümoloogilises kirjanduses esitatud kaks seletust. Esimese järgi on tegu deskriptiivtüvega, mida esindavad ka soome toro, torro, torri 'miski õieli olev (puu, oks, torbik jms); rumal, loll', torottaa, torrottaa 'püsti, õieli olla' (SKES: 1351; EEW: 3249-3251; SSA 3: 312; EES: 542). Tüvel on samuti eesvokaalne variant, mis on läänemeresoome keeltes laiemalt levinud. Seda esindavad nt eesti (Kodavere) töroli 'püsti (saba)', törokille 'mossis', (Vaivara, Juuru) törus,

\footnotetext{
Vanemates sõnaraamatutes ei ole homonüüme eraldi märksõnadena esitatud. Nii on Thor Hellel samas märksõnaartiklis ka tähendus 'der Zanck' ['tüli'] (Helle 1732: 190) ja Hupelil 'Baß; Zank' ['bass; tüli'] (Hupel 1818: 251), mis seostuvad etümoloogiliselt teiste tüvedega, vrd sm tora 'sõnelus, tüli', ee tõrelema ja ee torisema.
} 


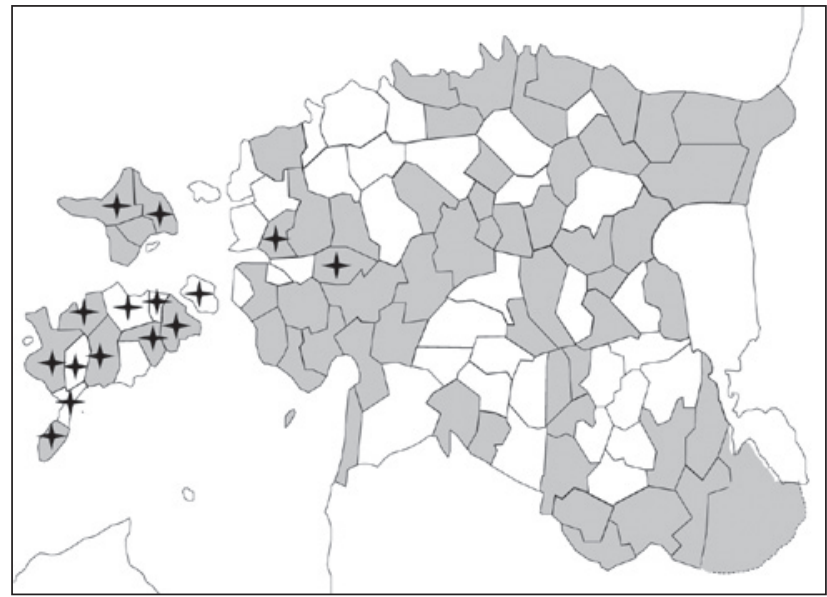

toru, toro

Kaart 3. toru, tori eesti murretes

törös 'mossis; õieli', (Lüganuse) törökalli' (huuled) torus', (Vaivara) törölle 'püsti (saba)' (VMS II: 585-586; vt ka SSA 3: 364), soome törö 'püstine, sageli sarvekujuline ese, anum vms; torbik', törrö 'torbik, rull', töröttää 'püsti, õieli olla; paigal istuda', törröttää 'välja ulatuda, püsti, õieli, harali olla' (SKES: 1507-1508; SSA 3: 364), karjala törö (Suistamo) 'alemaale püstitatud koonusekujuline varjualune', törö, töröńe (Tver) 'anuma tila; kapuuts, peakott', törööli (Tver) 'väike mõrd', törötteä, törrötteä 'paigal istuda', törö̈ttiä (Tver) 'välja ulatuda, püsti olla; looderdada, tegevuseta olla' (KKS: 389-390; Punžina 1994: 315; SKES: 1507-1508; SSA 3: 364). Siia võib kuuluda ka isuri törö(i) 'torn' (Nirvi 1971: 618), millele on tähelepanu juhtinud artikli retsensent. Seletus eeldab tähendusarengut 'miski esileulatuv, õieli olev' > 'pikk silindriline õõneskeha'. Kahtlemata leidub eespool esitatud läänemeresoome näidete hulgas niisuguseid, mille puhul selline tähendusnihe on tajutav (nt 'torbik, rull', 'anuma tila'), kuid toru esmane tunnus näib olevat siiski pigem õõnsus, läbitavus, kui esileulatuvus.

Teise seletuse järgi on eesti toru, soome toro etümoloogiliselt seotud läänemeresoome tüvega *torvi, mille vasted on eesti tõri, tõrv : tõrve '(sarve-, pasunakujuline) toru, sarv', soome, isuri, karjala torvi '(karja)pasun; toru', karjalas ka 'kangarull', ja vepsa toŕv 'karjapasun' ning mis on balti laen, vrd leedu tauré 'karikas, peeker; kupusarv', läti taure '(karja-, jahi)pasun, sarv' (vt nt SKES: 1357-1358; SSA 3: 313; EES: 562). Seda arvamust on väljendanud Lauri Kettunen (1938: 427), kelle järgi eesti tori, 
toru $<*$ torvi, ning Osmo Nikkilä (2002: 131-132), kelle arvates soome toro lähtub sõna torvi deminutiivtuletisest torvo, milles $v$ on labiaalvokaali eest kadunud (eesti vastet Nikkilä ei kommenteeri). Arvatavasti on Nikkilä nimetatud võimalust peetud silmas ka „Eesti keele sõnaraamatus“, kus tuletuskäiku täpsustamata (seda ei võimalda sõnaraamatu kokkusurutud vorm) peetakse eesti toru, soome toro tuletiseks tüvest *torvi (EKS). Et kõigis allikates on eesti toru ja/või soome toro seost tüvega * torvi käsitletud väga napilt, analüüsin järgnevalt seda etümoloogiat üksikasjalikumalt.

Eesti toru on deminutiivi *torv-o(i) ootuspärane vaste, sest teatavasti on eesti keeles $v$ kadu labiaalvokaali kõrval tavaline (vt nt Kask 1980: 15-16; Kettunen 1962: 116-117). Võrreldagu näiteks labiaalvokaalset sufiksit sisaldavaid tuletisi aru $(<*$ arv-o) ja kasu $(<* k a s v-o)$. Esmapilgul võib näida, et toru kohta on ka teine seletusvõimalus. Kuna eesti murretes esineb ka $v$ vokaalistumist, st muutust $v>u$, kui $v$ on pärast lõpukadu sattunud sõna absoluutsesse lõppu (Kettunen 1962: 116-117), tundub samuti mõeldav kujunemiskäik *torvi $>$ *torv $>$ toru (vrd eespool viidatud Kettunen 1938: 427). Tegelikult ei tohiks see võimalus arvesse tulla, sest murretes, kus esineb niisugust $v$ vokaalistumist, on ülejäänud paradigmavormides $v$ säilinud, nt karv > karu : karva (EMS II: 786), kuiv > kuju : kuiva (EMS III: 968), latv> ladu : ladva (EMS IV: 1003). Seevastu toru muutevormides $v$-häälikut ei esine.

Ka eesti murdevariandi tori kujunemist saab seletada $v$ kao põhjal: eesti murretes esineb $v$ kadu ka $i$ ees (Kask 1980: 15-16; Kettunen 1962: 116-117). Selliseid kaojuhte on rööpvariantidena kirjakeeldegi jõudnud, nt põlv põli, talv tali. Konsonandile järgnenud $v$ kadu $i$ eest on muu hulgas iseloomulik saarte murdele (Lonn, Niit 2002: 21), st alale, kus tori esineb. Seal on kirja pandud niisugused ainsuse nominatiivi vormid nagu järi 'järv', sari 'sarv', pili 'pilv' (ibid.), sealsamas on registreeritud ka *torvi vaste tõri töri (EMSUKA; VMS II: 585; vt kaart 4). Nendegi sõnade obliikvakäänetes on $v$ siiski säilinud (genitiivivormid järve, sarve, pilve, tõrve törve, EMS II: 333; EMSUKA), sest nendes vormides paikneb $v$ tüvevokaali $e$ ees. ${ }^{6}$ Kuna saarte murde sõna tori 'toru' genitiivivorm on tori, siis ei saa tegu olla $e$-tüvelise sõna *torvi : *torven vastega. tori võib aga lähtuda deminutiivtuletisest * torve-i. Selline deminutiiv olekski *torvi kui $e$-tüvelise sõna puhul algsem, sest * oi-sufiks on hakanud levima

${ }^{6}$ Kohati esineb siiski $v$-kaolise tüvega obliikvakäänete vorme, nt pilide 'pilvede', saride 'sarvede', saridega 'sarvedega', töri : töri (EMSUKA). 
$a$-tüvelistest sõnadest, kus deminutiivse $*_{-} i$ liitumisel tekkis diftong $*_{\text {-oi }}$ (Laanest 1975: 140). Et järgsilpide ei-diftong on läänemeresoome keeltes muutunud $i$-ks (vt nt Laanest 1975: 73, 140), pidi deminutiiv *torvei selle muutuse tulemusel nominatiivis kokku langema tuletusalusega *torvi, kuid oli erinevalt sellest $i$-tüveline sõna (st *torvi : *torvin). See võis olla üks põhjus, miks hakati enamikus eesti murretes eelistama (eeldatavasti uuemat) *o-deminutiivi *torvo : *torvon. Arhailine $i$-tüveline *torvi : *torvin säilis ainult perifeerias saarte murdes. Kuna selles sõnas on $v$ kogu muuteparadigmas $i$ ees, on ka $v$ hilisem kõiki sõnavorme hõlmav kadu ootuspärane.

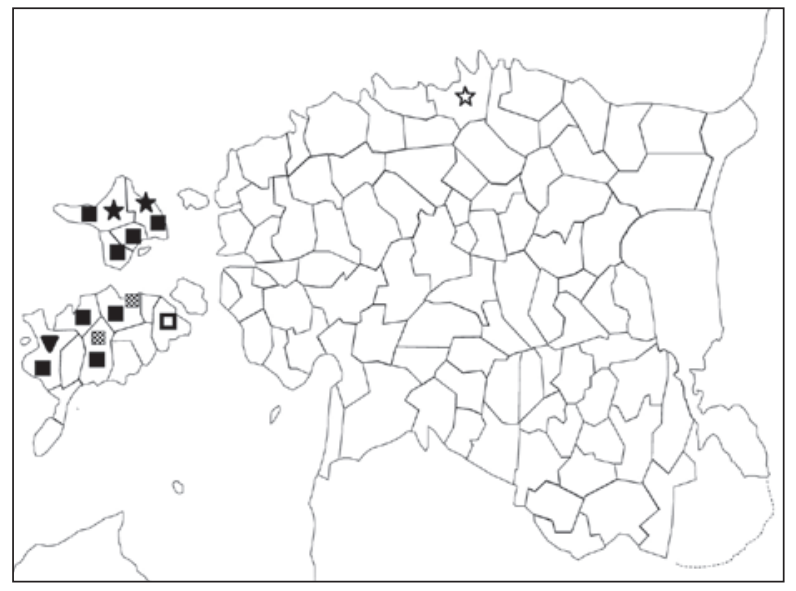

ㅁ tõri: tõrve

- töri : törve

쁨 töri : töri

$\star \quad t o ̈ r v(e):$ törve

is torv: torve

$\nabla$ töru

Kaart 4. tõri, tõrv eesti murretes

Seda, et eesti sõnad toru ja tori on tuletusseose kaudu seotud läänemeresoome tüvega *torvi, ei tohiks kahtluse alla seada ka asjaolu, et *torvi eesti vastes on toimunud häälikuline areng $*_{O}>\tilde{o}^{7}$, kuid sõnades toru ja tori on algne $o$ säilinud. Leidub teisigi näiteid, kus sama juurtüve sisaldavates

7 o-lised vasted tõŕv ja tõri 'Sprachrohr, hölzernes Hüterhorn' ['kõnetoru, puust karjasepasun'] on registreeritud 19. sajandi murdekeeles (Wiedemann 1973 [1893]: 1188-1189). 20. sajandil kogutud murdekeeles on *torvi vaste registreeritud peamiselt saarte murdes, kus on kirja pandud variandid töri, törv(e) ja töru, sest enamikus selle murde murrakutes vastab $\tilde{o}$-le $\ddot{o}$. Ainult Pöide murrakus on registreeritud $\tilde{o}$-line tõri. Algupärase $o$-ga vaste torv on registreeritud Põhja-Eesti rannikul Kuusalu murrakus, kus õ-häälikut ei esine. (EMSUKA; VMS II: 585; vt kaart 4) Varianti torv on peetud soome keelest laenatuks (SKES: 1358; SSA 3: 313). 
sõnades on kord toimunud muutus $o>\tilde{o}$, kord aga algne $o$ säilinud, vrd nt sõba ja sobima $(<\operatorname{lms} *$ sopa $)$, tõrelema ja tore $(<\operatorname{lms} *$ tora $)$. Algne $o$ on säilinud ka tüve *torvi tuletises torbik, murdes ka torvik (EEW: 3240; VMS II: 530; Wiedemann 1973 [1893]: 1175).

Semantika poolestki ei ole takistusi sõnade toru ja torvi ühendamiseks. Tähendusnihe 'sarv' > 'toru' on loomulik, ühendav tunnus on siin just õõnsus, läbitavus. Mitmes läänemeresoome keeles (soome, isuri, karjala) ongi sõnal torvi lisatähendus 'toru'. Samuti meenutatagu, et toru on eesti keeles esimest korda ehk Gösekeni sõnaraamatus kirja pandud just sarve, pasuna tähenduses.

Soome murretes esineb $v$ kadu labiaalvokaalide ees, millele osutab Nikkilä, hoopis harvem. Kadu on häälikuseaduslik edelamurretes ja AlaSatakunta Loimaa murdes, $u$ ees ka Peräpohjala murretes, sõnuti mujalgi (Rapola 1966: 294-295). Sõna toro on levinud edelamurretes, kohati Hämes, Karjala kannasel ja Ingerimaal (SSA 3: 312). Levikuala kattub seega $v$ kao piirkonnaga vaid osaliselt. Vahest on mõeldav $v$-kaolise sõnakuju levimine üle murdepiiride või selle (vähemalt osaline) laenamine eesti keelest. On ju eesti toru laenatud liivi keeldegi, mis võiks osutada selle sõna ekspansiivsusele. Soome toro levikupiirkond eesti laenu võimalusele vastu ei räägi. Võrdluseks märgitagu, et Soome murretes on registreeritud ka sõnast torvi moodustatud deminutiiv torvo 'torbik, sarvetaoline rull (kangast, tohtu vms)', milles $v$ on säilinud (SKES: 1357).

Tähelepanuta ei saa siiski jätta mõningaid häälikulisi vastuargumente. Kui toru lähtub tüvest *torvi, võiks eeldada mõningaid $v$ jälgi eesti murretes, sest sõnuti leidub näiteid $v$ säilimisest labiaalvokaali ees, vrd nt Võru murdes ja Kodaveres arv : arvu arvo, Tartu murdes kohati aru : arvu, kirderannikumurretes 'arv $(u) \sim$ 'arv(o) : 'arvu 'arvo 'aru, mõistus jne' (EMS I: 446). Selliseid jälgi ei paista. ${ }^{8}$ Tuleb ka möönda, et soome varianti tori ei ole võimalik $v$ kaoga seletada.

Nii võib eesti toru vähemalt osaliselt olla *o(i)-liiteline deminutiivtuletis tüvest *torvi 'sarv'. Üheselt selgeks ei saa sõna päritolu pidada, sest see võib seostuda ka läänemeresoome tüvega *tor $V$ - tör $V$ - 'esile ulatuma, õieli olema; esile ulatuv, õieli'.

8 Artikli retsensendi hinnangul räägib oletatavale $v$ kaole sõnas toru vastu Lutsi murrakus registreeritud toro 'pakktaru sülemite püüdmiseks' (EMSUKA): Lutsis oleks ootuspärane $v$ säilimine. Lutsi sõna, mille semantiline erinevus on märgatav ja mille kohta on napilt andmeid, ei tarvitse aga tingimata olla toru vaste. 


\section{Kirjandus}

Aavik, Johannes 1919. Uute sõnade sõnastik. Tartu: Istandik.

Aavik, Johannes 1921. Uute ja vähem tuntud sõnade sõnastik. Tallinn: A. Keisermann.

EES = Iris Metsmägi, Meeli Sedrik, Sven-Erik Soosaar 2012. Eesti etümoloogiasõnaraamat. Eesti Keele Instituut. Tallinn: Eesti Keele Sihtasutus. http://www.eki.ee/dict/ety/.

EEW = Julius Mägiste 1982-1983. Estnisches etymologisches Wörterbuch I-XII. Helsinki: Finnisch-Ugrische Gesellschaft.

EKMS = Andrus Saareste 1958-1963. Eesti keele mõisteline sõnaraamat I-IV. Dictionnaire analogique de la langue estonienne. Avec un index pourvu de traductions en français. (= Eesti Teadusliku Seltsi Rootsis väljaanne nr 3.) Stockholm: Vaba Eesti.

EKSS $=$ Eesti keele seletav sõnaraamat, 1-6, 2009. „Eesti kirjakeele seletussõnaraamatu“ 2., täiend. ja parand. tr. Toim. Margit Langemets, Mai Tiits, Tiia Valdre, Leidi Veskis, Ülle Viks, Piret Voll. Eesti Keele Instituut. Tallinn: Eesti Keele Sihtasutus. http://www.eki.ee/dict/ekss/.

EMS = Eesti murrete sõnaraamat I-VI, 1994-2019. Eesti Teaduste Akadeemia . Eesti Keele Instituut. Tallinn: Eesti Keele Sihtasutus. http://www.eki. ee/dict/ems/.

Göseken, Heinrich 1660. Manuductio ad Linguam Oesthonicam. Anführung Zur Öhstnischen sprache/ Bestehend nicht alleine in etlichen præceptis und observationibus,/ Sondern auch/ In Verdolmetschung vieler Teutschen Wörter. Reval. Faksiimile: http://www2.kirmus.ee/grafo/ index.php?ID=243.

Helle, Anton Thor 1732. Kurzgefaßte Anweisung zur Ehstnischen Sprache, in welcher mitgetheilet werden I. Eine Grammatica. II. Ein vocabularium. III. Proverbia. IV. Ænigmata. V. Colloquia. Halle: Stephan Orban.

Hupel, August Wilhelm 1780. Ehstnische Sprachlehre für beide Hauptdialekte/ den revalschen und den dörptschen; nebst einem vollständigen Wörterbuch. Riga, Leipzig: Hartknoch.

Hupel, August Wilhelm 1818. Ehstnisches Wörterbuch für die beiden Hauptund die darunter begriffenen Neben-Dialekte. Erster Theil, welcher das ehstnisch-deutsche Wörterbuch enthält. - Ehstnische Sprachlehre für die beyden Hauptdialekte, den revalschen und dörptschen, nebst einem vollständigen ehstnischen Wörterbuche. Mitau: Steffenhagen. Faksiimile: http://dspace.ut.ee/handle/10062/46591.

Kask, Arnold 1980. Eesti keele ajalooline grammatika. Häälikulugu 2. 2. tr. Tartu: Tartu Riiklik Ülikool.

Kettunen, Lauri 1938. Livisches Wörterbuch mit grammatischer Einleitung. (= Lexica Societatis Fenno-Ugricae 5.) Helsinki: Suomalais-Ugrilainen Seura. 
Kettunen, Lauri 1962. Eestin kielen äännehistoria. Kolmas painos. (= Suomalaisen Kirjallisuuden Seuran toimituksia 156.) Helsinki: Suomalaisen Kirjallisuuden Seura.

Kingisepp jt 2010 = Valve-Liivi Kingisepp, Kristel Ress, Kai Tafenau 2010. Heinrich Gösekeni grammatika ja sõnastik 350. Toim. Külli Habicht, Külli Prillop. Tartu: Tartu Ülikooli eesti ja üldkeeleteaduse instituut.

KKS = Karjalan kielen sanakirja 6. T-Ö, 2005. (= Lexica Societatis FennoUgricae XVI, 6.) Helsinki: Suomalais-Ugrilainen Seura.

Kobolt, E[rich] 1931. Saksa laensõnu eesti käsitöölis-keeles. Eesti viplati etümoloogia. - Eesti Keel 10, 149-157.

Laanest, Arvo 1975. Sissejuhatus läänemeresoome keeltesse. Tallinn: Eesti NSV Teaduste Akadeemia Keele ja Kirjanduse Instituut.

Lonn, Varje, Ellen Niit 2002. Saarte murde tekstid. (= Eesti murded VII.) Tallinn: Eesti Keele Instituut.

Nikkilä, Osmo 1999. Sporadischer Konsonantenwechsel im Ostseefinnischen. Finnisch-ugrische Mitteilungen 21/22, 129-160.

Nikkilä, Osmo 2002. Suomen sanojen alkuperät päätökseen. - Virittäjä 106, 124-136.

Nirvi, R. E. 1971. Inkeroismurteiden sanakirja. (= Lexica Societatis FennoUgricae XVIII.) Helsinki: Suomalais-Ugrilainen Seura.

Ojansuu, Heikki 1916. Suomen kielen tutkimuksen työmaalta. Sarja esitelmiä 1. Jyväskylä.

Punžina 1994 = А. В. Пунжина 1994. Словарь карельского языка (тверские говоры). Карельский научный центр российской академии наук. Институт языка, литературы и истории. Петрозаводск: Карелия.

Rapola, Martti 1966. Suomen kielen äännehistorian luennot. (= Suomalaisen Kirjallisuuden Seuran Toimituksia 283.) Helsinki: Suomalaisen Kirjallisuuden Seura.

Raun, Alo 1982. Eesti keele etümoloogiline teatmik. Rooma, Toronto: Maarjamaa. SKES $=$ Yrjö H. Toivonen, Erkki Itkonen, Aulis J. Joki 1955-1981. Suomen kielen etymologinen sanakirja I-VII. (= Lexica Societatis Fenno-Ugricae XII, 1-7. Tutkimuslaitos „Suomen Suvun“ julkaisuja III. Kotimaisten kielten tutkimuskeskuksen julkaisuja 2.) Helsinki: Suomalais-Ugrilainen Seura.

SSA = Suomen sanojen alkuperä. Etymologinen sanakirja 1-3, 1992-2000. Päätoim. Erkki Itkonen, Ulla-Maija Kulonen. (= Suomalaisen Kirjallisuuden Seuran toimituksia 556. Kotimaisten kielten tutkimuskeskuksen julkaisuja 62.) Helsinki: Suomalaisen Kirjallisuuden Seura, Kotimaisten kielten tutkimuskeskus.

Vaba, Lembit 2016. Alternatiivseid etümoloogiaid II. - Emakeele Seltsi aastaraamat 61 (2015). Peatoim. Mati Erelt. Tallinn: Teaduste Akadeemia Kirjastus, 253-262. doi:10.3176/esa61.12 
VKS = Vadja keele sõnaraamat. Vad́daa tšeelee sõna-tširja. Словарь водского языка, 2013. 2., täiend. ja parand. tr. Peatoim. Valmen Hallap. 2. trüki toim. Silja Grünberg. Eesti Keele Instituut. Tallinn: Eesti Keele Sihtasutus. http://portaal.eki.ee/dict/vadja/.

VMS = Väike murdesõnastik I-II, 1982-1989. Toim. Valdek Pall. Koost. Anu Haak, Evi Juhkam, Marja Kallasmaa, Ann Kask, Ellen Niit, Piret Norvik, Vilja Oja, Aldi Sepp, Jaak Simm, Jüri Viikberg. Eesti NSV Teaduste Akadeemia Keele ja Kirjanduse Instituut. Tallinn: Valgus. http://www. eki.ee/dict/vms/.

Väinaste, J. 1925. Häälikvaheldus-nähtustest eesti keeles. - Eesti Keel 5-6, 89-111.

Wiedemann, Ferdinand Johann 1869. Ehstnisch-deutsches Wörterbuch. St. Petersburg.

Wiedemann, Ferdinand Johann 1973 [1893]. Eesti-saksa sõnaraamat. Neljas, muutmata trükk teisest, Jakob Hurda redigeeritud väljaandest. Vierter unveränderter Druck nach der von Jakob Hurt redigierten Auflage. Tallinn: Valgus.

ÕS 1918 = Eesti keele õigekirjutuse-sõnaraamat, 1918. Eesti Kirjanduse Seltsi väljaanne. Tallinn: K.-Ü. „Rahvaülikooli“ kirjastus. Faksiimile: https:// www.etera.ee/zoom/9460/view?page $=1 \& p=$ separate\&tool $=$ info.

ÕS 2018 = Eesti õigekeelsussõnaraamat ÕS 2018. Toim. Maire Raadik. Koost. Tiiu Erelt, Tiina Leemets, Sirje Mäearu, Maire Raadik. Eesti Keele Instituut. Tallinn: Eesti Keele Sihtasutus. http://www.eki.ee/dict/qs/.

\section{Sõnavarakogud ja võrgumaterjalid}

$\mathbf{E K S}=$ Eesti keele sõnaraamat 2019. https://sonaveeb.ee/.

EMSUKA = Eesti murrete ja soome-ugri keelte arhiiv Tallinnas Eesti Keele Instituudis. 


\title{
On the origin of the words tiide, tiidakil and toru
}

\author{
IRIS METSMÄGI
}

The adverb tiide 'awry, aslant' and the related tiideviltu id., identified as dialect words in modern Estonian dictionaries, appear primarily in the Islands and Western dialects. The standard language also includes the adverb tiidakil 'sunk askew, falling over; crooked, aslant', apparently sharing the same stem, which has also been observed in dialects, recorded primarily in the 19th century, in the meaning of 'folded into a triangle'. Julius Mägiste conjectured that the adverb tiidakil (? also tiide, tiideviltu) is etymologically related to the stem tiib 'wing'. This article suggests a development path wherein tiide is a shortening of the compound word tiideviltu, which in turn developed via sporadic plosive alternation and folketymological interpretation from the loan word piidevint, piidevinti 'headwind, against the wind' (< Low German bi de wind or Dutch bij de(n) wind), compare to the dialectal variant tiidevinti. The word tiide may have influenced the meaning of the word tiidakil in the standard language, despite its perhaps different origin.

The Estonian word toru 'pipe, tube' and its Finnish equivalent toro '(mill) hopper; gutter, pipe; jug spout' have been etymologically connected to the Finnic stem tor $V_{-} \sim$ tör $V$ - 'to extend forward, be stretched out'. Osmo Nikkilä regards Finnish toro as a diminutive derivative of the Finnic stem *torvi 'horn' (a Baltic loan), in which the $v$ has been elided before a labial vowel (*torv-o $>$ toro). The article analyzes this same possible explanation for Estonian toru. In Estonian the elision of the phoneme $v$ before a labial vowel is common. In dialects, $v$ can be elided also between a consonant and $i$. The diminutive source form explains the absence of $v$ in both the word toru $(<*$ torvo(i)) and its dialectal variant tori $(<*$ torvei $)$ in all case forms. The semantic shift 'horn' $>$ 'pipe, tube' is natural as well.

Keywords: Estonian, Estonian dialects, lexicology, etymology

Iris Metsmägi

eesti keele ajaloo, murrete ja soome-ugri keelte osakond

Eesti Keele Instituut

Roosikrantsi 6

10119 Tallinn

iris.metsmagi@eki.ee 